Tuberkulose 1951;8:228

\title{
Contents, Vol. 8, No. 4, 1951
}

\section{INDEX}

Haefliger, Zur Entstehung der Lungentuberkulose

Landolt, Verschwartende Pleuritis exsudativa bei Bronchustuberkulose . . 238

Mauderlí, Uber die Entstehung unspezifisch-entzündlicher Hilusverände-

rungen

245

Mordasiní, Beitrag zur niodernen Behandlung der tuberkulösen Meningitis

beim Erwachsenen

Ott, Die Tuberkulose-Mortalität und -Morbidität inihrenBeziehungen zu den Fortschritten in der Tuberkulosebekämpfung und den sozialen Ein-

richtungenim Kanton Solothurn 1900-1950 266

Ott und Tanner, Uber unsere Resultate mit Streptomycin und PAS in der

Behandlung der Urogenitaltuberkulose 291

Schachenmann, Uber den Verlauf primärer Hauttuberkulosen

Steiger, Siliko-Tuberkulose 310

Steíner, Exstirpation des Ganglion stellatum bei Asthma bronchiale .... Suter und Iselin, Zur Frage der Entstehung der Lungenphthise des Er wachsenen aus perforierenden Hiluslymphknoten 341

Wacker, Avantages de la tomographie latérale du thorax

Wehrlín, Zur Differentialdiagnose der Meningitis tuberculosa

Wernlí-Haessig, Team-Work in der Behandlung der Lungenkranken .... 